\title{
Educação Médica em tempos de pandemia: Novas Perspectivas
}

\author{
Samya H. Mehanna
}

Médica Patologista

\author{
Mestre em Ensino de Ciências da Saúde \\ Docente de Patologia Faculdades Pequeno Príncipe (FPP) e Faculdade \\ Evangélica Mackenzie do Paraná (FEMPAR)
}

A pandemia do novo coronavírus causou interrupção sem precedentes na educação médica e nos sistemas de saúde em todo o mundo. A partir do seu início, professores e estudantes têm enfrentado o desafio de se adaptar às recentes dificuldades. Nos deparamos com a situação entre o desejo de estar na linha de frente do combate e o medo da contaminação, além da necessidade de reinventar as estratégias pedagógicas para manutenção do distanciamento social, garantindo a segurança e integridade física de todos. O COVID-19 afetou, negativamente, determinados aspectos da educação médica. Por outro lado, foram geradas oportunidades para que os alunos percebessem a natureza dinâmica do conhecimento médico, associado ao domínio dos conceitos-chave de biologia, sociologia, psicologia e ciência, os quais são essenciais para os médicos enfrentarem esta inédita ameaça à saúde da população mundial.

Diante deste cenário, para dar continuidade ao processo ensino-aprendizagem universitário, precisamos recorrer ao uso de tecnologias de informação e comunicação (TICS). A discussão sobre como estruturar o currículo médico buscando acompanhar o desenvolvimento das TICs vem sendo debatida há muito tempo, mas a questão ganhou notoriedade após a migração para atividades online durante o isolamento social imposto pelo COVID-19. Além disso, a centralidade docente e o pouco protagonismo dos estudantes foram evidenciados durante este período de crise.

A formação adequada de novos médicos envolve o desenvolvimento de competências, incluindo conhecimentos, habilidades e atitudes fundamentais para sua atuação profissional futura. Neste contexto, ocorre aperfeiçoamento de habilidades técnicas que até então apresentavam escassas alternativas para a educação remota. Dessa forma, os educadores inovaram as atividades didático-pedagógicas, por meio da digitalização das salas de aula e uso recursos eletrônicos na prática médica geral, buscando proporcionar aos estudantes uma experiência efetiva e motivadora.

Entre as estratégias empregadas, destacam-se a utilização de plataformas de videoconferência (Microsoft

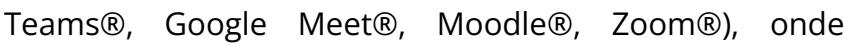
ocorrem reuniões virtuais que deveriam tornar o aluno um protagonista do processo ensino-aprendizagem, incorporando o uso de metodologias ativas, preferencialmente em pequenos grupos para facilitar a interatividade. No Ambiente Virtual de Aprendizagem (AVA), disponibilizam-se as gravações das aulas, os fóruns para solucionar dúvidas, servindo como espaço de comunicação entre estudantes e professores. Ademais, a avaliação de forma on-line foi uma novidade, prejudicando as instituições que já objetivavam não aplicar simples testes de memorização, mas de raciocínio e exame clínico objetivo e estruturado (OSCE).

No ciclo básico, disciplinas práticas, como Anatomia e Histologia, demonstraram certa dificuldade na adaptação para a modalidade on-line.

Contudo, a utilização de instrumentos visuais simuladores da realidade puderam mitigar a ausência presencial de cadáveres e lâminas histológicas, por exemplo. Tais medidas amenizaram, também, as adversidades decorrentes do distanciamento físico entre docentes e alunos, tornando o ensino remoto mais dinâmico. 
A evolução dessas adaptações, somadas ao ganho de experiência dos docentes ao longo dos meses iniciais da pandemia, foram cruciais para a manutenção da qualidade da modalidade a distância, em especial para disciplinas pré-clínicas de componente prático, como é também a Patologia. Porém, o desafio é maior quando pensamos em atividades clínicas e estágios que contemplem a vivência em enfermarias e ambulatórios. Como poderíamos suprir a falta de contato do estudante com o paciente? Certamente existem enormes limitações para as experiências clínicas e cirúrgicas no que concerne o ensino remoto.

Devemos projetar soluções inovadoras, acompanhando os avanços da telemedicina, proporcionando, desde de visitas virtuais na beira do leito, consultas ambulatoriais remotas, na tentativa de diminuir os impactos no desenvolvimento de habilidades clínicas. É de se imaginar, também, rotinas médicas que utilizem recursos de imagem, como radiologia e endoscopia, possam ser transmitidas ao vivo para os estudantes com o simples espelhamento de câmeras com alta resolução. Até mesmo aprendizagem cirúrgicas televisionadas em tempo real, permitindo, inclusive, comunicação bidirecional entre o aluno e a equipe cirúrgica através de microfone. Ainda, construção de casos clínicos interativos simulados, onde pacientes reais compõe o enredo, que podem ser resolvidos de forma síncrona entre estudante e preceptor, o qual avalia seu desempenho, sempre direcionando para atitudes guiadas pela Medicina Baseada em Evidências.

Parece uma experiência impossível? Estudos apontam este "novo normal" como realidade em alguns países desenvolvidos. Contudo, dentro da conjuntura brasileira, teremos possibilidades amplas e desiguais, sejam regionais ou no âmbito público-privado. Independente disso, de maneiras mais ou menos intensas, o impacto na formação médica parece generalizado. Em todo o mundo, os cursos de medicina redesenharam seus currículos para garantir que a força de trabalho do médico em formação fosse mantida.

Certamente, para alcançarmos a implementação de um eficaz ensino a distância, além de obter infraestrutura, a capacitação dos docentes para o emprego correto das TICS é vital. Essa problemática está de acordo com o proposto pelas Diretrizes Curriculares Nacionais (DCNs) para o curso de Medicina, datada de 2014, que já exige aos cursos médicos a constituição de um Núcleo Docente Estruturante (NDE). Tal grupo é atuante justamente no processo de concepção, consolidação, avaliação e contínua atualização e aprimoramento do Projeto Pedagógico do Curso, com estrutura e funcionamento previstos mantendo permanente o Programa de Formação e Desenvolvimento da Docência em Saúde, por meio do domínio conceitual e pedagógico, que engloba estratégias de ensino ativas, pautadas em práticas interdisciplinares de integração curricular, de modo a assumirem maior compromisso com a transformação da escola médica, a ser integrada na vida cotidiana dos docentes, estudantes, trabalhadores e usuários dos serviços de saúde.

E por quê não, atualmente, estimular a aplicação com excelência dessas ferramentas para o ensino médico à distância? O corpo docente precisou usar conhecimentos em psicologia e sociologia para analisar os desafios éticos do racionamento do cuidado no formato virtual, incluindo a dedicação ao paciente no espectro da humanização, insegurança dos profissionais da área, do acesso precário ao sistema para parte da população, além de empecilhos de cunho político de restrição da autonomia pessoal, bem como o combate às "fake news" durante este processo.

Entretanto, precisamos de estudos futuros capazes de avaliar a eficácia destas estratégias na formação com qualidade dos novos médicos. Mas, até certo ponto, existem abordagens possíveis que podem ser usadas sem prejudicar o desenvolvimento de competências dos profissionais contemporâneos. Passados tantos meses do início da pandemia, as entidades e instituições de ensino já buscam avaliar o impacto da suspensão das aulas presenciais e atividades práticas sobre os estudantes.

Sabemos que existem múltiplas falhas na formação médica atual mesmo no modelo presencial e tradicional. Podemos acreditar então, que este momento é apropriado para instaurar mudanças, devendo haver apoio e entusiasmo no fornecimento de soluções válidas, bem como prover treinamento online e experiência clínica virtual que venham a ser aplicadas mesmo após a volta de nossas rotinas. Ao mesmo tempo, fica a reflexão de como esse período prolongado de crise implicou na vida dos estudantes de medicina, tais como o bem-estar psicológico e o impacto nas trajetórias acadêmicas. Embora a pandemia COVID-19 nos traga a ideia de paralisação no ensino, é provável que nos próximos anos seja reconhecida como um catalisador para a transformação da educação médica.

Dessa forma, o afastamento de estudantes de medicina dos estágios clínicos pode ter implicações significativas no futuro, havendo dúvidas sobre em qual momento este déficit será compensado, sendo angustiante aos já preocupados acadêmicos toda esta problemática. No entanto, a crise do coronavírus evidenciou questões já debatidas no ensino médico, como o papel central e autônomo do estudante nas atividades pedagógicas, focando a formação na experiência clínica, quebrando paradigmas gerados por um modelo tradicional de ensino, que não estava até então em consonância com o mundo 
moderno e os avanços tecnológicos.

Nas próximas décadas, ao olharmos para trás, veremos alunos capazes de perceber que não ficaram à margem neste período, como pensam. Ao contrário, certamente, criarão uma importante consciência sobre o significado de ser médico em virtude do que vivenciaram durante a pandemia. Por fim, o uso ampliado das TICS vieram e se enraizaram, e indubitavelmente continuarão no amanhã, reduzindo a carga horária presencial, facilitando e abrindo caminho ao ensino híbrido. 